ISSN: 0514-7336

DOI: http://dx.doi.org/10.14201/zephyrus2017801532

\title{
MATERIALES DEL PALEOLÍTICO SUPERIOR EN COVA NEGRA (XÀTIVA) Y SU INTERÉS PARA ESTABLECER LOS PROCESOS DE SU SECUENCIA ESTRATIGRÁFICA
}

\section{Upper Paleolithic materials from Cova Negra (Xàtiva) and its implications in the sequential stratigraphic processes}

\author{
Valentín Villaverde Bonilla* y Aleix Eixea Vilanova** \\ * Dpto. de Prehistoria, Arqueología e H. a Antigua. Facultad de Geografía e Historia-Uv. C/ Blasco Ibáñez, 28. \\ 46010 Valencia. Correo-e: valentin.villaverde@uv.es \\ ** Instituto Catalán de Paleoecología Humana y Evolución Social (IPHES). Zona Educacional. Campus Sescelades \\ URV. Edificio W3. 43007 Tarragona. Correo-e: aeixea@iphes.cat
}

Recepción: 16/01/2017; Revisión: 20/02/2017; Aceptación: 30/05/2017

\begin{abstract}
Resumen: En este trabajo se analizan los materiales líticos adscritos al Paleolítico Superior obtenidos en Cova Negra a lo largo de las campañas de excavación de los años 30, 50 y 80 del pasado siglo y en las campañas de 2013-2016. La atención se centra en el estudio de los soportes, los núcleos y el material retocado, y se efectúa una primera aproximación con respecto a la cronología y periodos a los que remiten las piezas retocadas. El principal interés de estos materiales reside en confirmar que la ocupación de la cavidad no se limitó al Paleolítico Medio, ni a momentos iniciales de la secuencia del Paleolítico Superior, lo que facilita una evaluación del alcance de los procesos de alteración postdeposicional registrados en la cavidad y cómo estos procesos afectaron a una buena parte de los niveles del Paleolítico Medio clásico y a la totalidad de los niveles del Paleolítico Superior. Estos datos permiten una mejor comprensión del relleno del yacimiento y explican también las dudas que reiteradamente la interpretación de la secuencia ha suscitado con respecto a la posición cronológica de los niveles superiores del Paleolítico Medio.

Palabras clave: Industria lítica; relleno sedimentario; Gravetiense; Solutrense; Magdaleniense; País Valenciano; Península Ibérica.
\end{abstract}

Aвstract: We approach Upper Paleolithic lithic materials from Cova Negra belonging to 30's, 50's, 80's and 2013-2016 field seasons. This article focuses on the characterization of blanks, cores, and tools with a preliminary chronology, specially, from retouched materials. The main interest is the Upper Paleolithic occupation and the evaluation of postdepositional processes documented in the cavity and how they impacted to Middle Paleolithic classic levels and to all Upper Paleolithic levels facilitating an evaluation of the extent of the processes of postdepositional alteration registered in the cavity and how these processes affected a good part of the levels of the classic middle Palaeolithic and to all the levels of the Upper Paleolithic. Data allow us a better depositional comprehension and they explain the problematic interpretations in relation with upper levels from Middle Paleolithic.

Key words: Lithic industry; Sedimentary package; Gravettian; Solutrean; Magdalenian; Valencian region; Iberian Peninsula. 


\section{Introducción ${ }^{1}$}

La Cova Negra de Xátiva es conocida en la bibliografía por su importante secuencia del Paleolítico Medio, el amplio conjunto de restos humanos recuperados en las distintas campañas de excavación realizadas en el yacimiento (Arsuaga et al., 2007) y los materiales líticos y restos óseos asociados a la frecuentación de la cavidad (Fig. 1) por las poblaciones neandertales (Villaverde et al., 2009; Martínez Valle, 2009; Guillem, 2009) $)^{2}$.

En la actualidad, como consecuencia de la revisión de la fauna recuperada en el yacimiento, se han reiniciado los trabajos de campo con la finalidad de precisar la secuencia cronológica del relleno, ya que los datos microfaunísticos permiten considerar que gran parte de la misma corresponde al Pleistoceno Medio final -MIs 6- y sólo los niveles superiores al inicio del Pleistoceno Superior -Mis 5-.

Esta propuesta (Villaverde et al., 2014), que matiza sensiblemente la visión que hasta hace poco se tenía de Cova Negra, se está viendo reforzada por la obtención de nueva información relativa a la dinámica de formación del relleno y permite, unida a los

1 La investigación de este trabajo, desarrollada dentro de PREMEDOC (GIUV2015-213), se ha beneficiado de las siguientes ayudas: "Paleolítico Medio y Superior en la vertiente mediterránea ibérica (Valencia y Murcia)" (HAR2014-52671-P) y "Más allá de la Historia: los inicios del poblamiento paleolítico valenciano” (PROMETEOII/2013/016).

2 Cf. también Eixea, A.: Caracterización tecnológica y uso del espacio en los yacimientos del Paleolitico medio de la región central del Mediterráneo Ibérico. Tesis doctoral defendida en 2015 en la Univ. de Valencia.

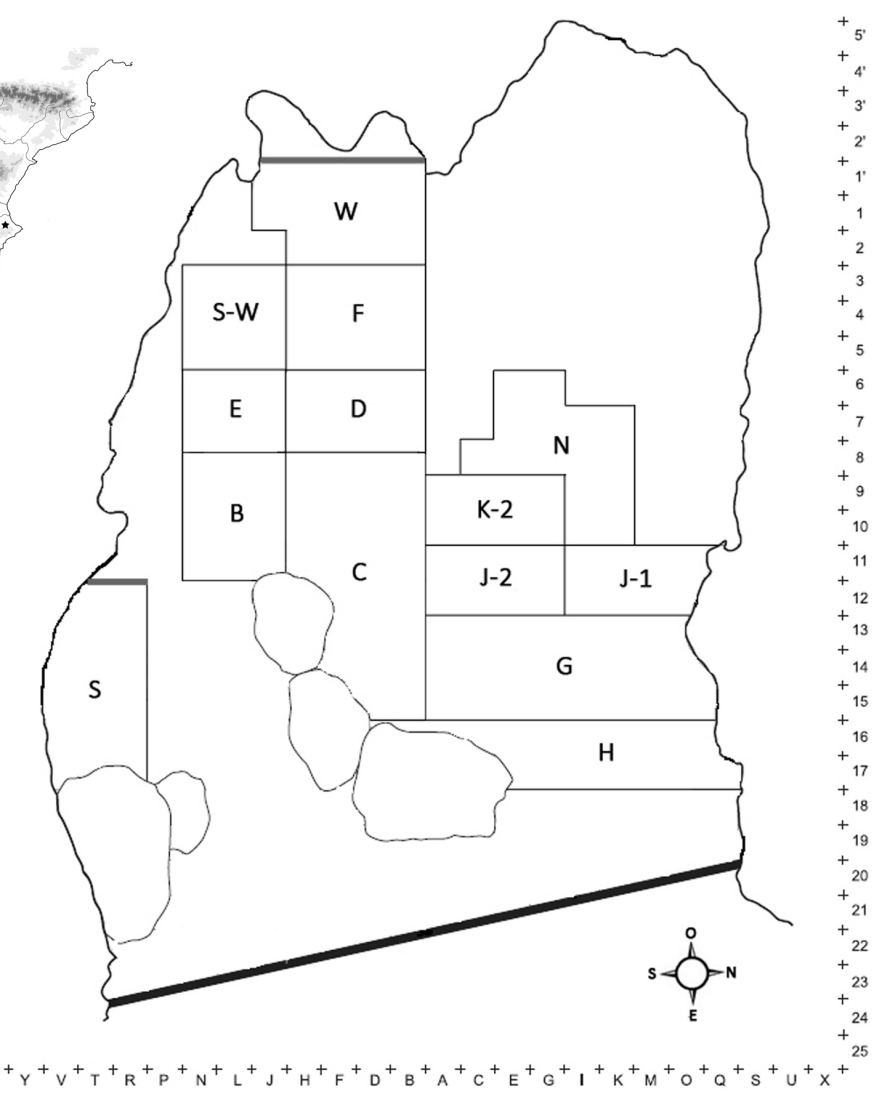

FIG. 1. Ubicación geográfica y planta de la cueva con indicación de los sectores excavados; con linea más ancha y gris se marca la posición de los cortes estratigráficos de referencia.

materiales recuperados precisamente en los últimos años, pensar que la cavidad presentó en su día no sólo niveles de ocupación que abarcarían gran parte del Paleolítico Medio antiguo y clásico, sino también otros cuya tipología apunta claramente a etapas correspondientes al Paleolítico Superior-MIs 3 y 2-.

Por el interés que ofrece a la hora de perfilar la problemática que acompaña la caracterización de las ocupaciones del Paleolítico Superior que pudieron registrarse en la cavidad, damos a conocer en este trabajo un conjunto de piezas que presentan inequívoca adscripción a distintas etapas de este periodo, y que provienen de un paquete revuelto, de desigual potencia, en el que se mezclan los restos líticos y óseos correspondientes tanto a estas cronologías como al Paleolítico Medio. El alcance de este fenómeno ha podido ser evaluado con cierta precisión a partir de los datos obtenidos en el proceso de 
excavación de la parte meridional del yacimiento, zona en la que para excavar los niveles del Paleolítico Medio antiguo se ha debido proceder al levantamiento previo de un paquete de tierras revueltas que, con desigual potencia, cubría los niveles en posición primaria en esa zona de la cavidad.

El interés de estos materiales, más allá de la importancia que tiene fijar la presencia de determinadas fases del Paleolítico Superior regional en el sitio y evaluar la amplitud del poblamiento de esta etapa, reside en la información que proporcionan sobre la compleja alteración postdeposicional sufrida por los paquetes superiores del yacimiento y permite entender algunos aspectos relativos al mismo que han tenido fuerte influencia en la interpretación de las industrias líticas y la cronología de los niveles arqueológicos que se conservan no alterados.

En los trabajos efectuados en los años ochenta del pasado siglo el número de piezas de tipología propia del Paleolítico Superior recuperadas en el levantamiento del nivel superficial revuelto fue reducido (Villaverde, 1984). Y algo similar ocurrió en las anteriores excavaciones de los años veinte $y$ cincuenta.

Para dar cuenta detallada de esta problemática, trataremos primero de los datos e informaciones disponibles sobre la existencia de ese paquete superficial revuelto en las campañas anteriores a los años $80 \mathrm{del}$ pasado siglo, y los complementaremos con la información proporcionada por las campañas en curso y con los materiales recuperados en los años ochenta.

\section{Las excavaciones de Viñes y Jordá}

Viñes llamó la atención, en sus escasas y cortas notas publicadas sobre las excavaciones practicadas en Cova Negra, sobre dos aspectos que merecen particular atención: la cavidad, por su posición en un punto de paso estratégico y transitado, fue un lugar en el que la presencia humana y el uso, incluso, del recinto como corral generaron intensos procesos de remoción; en algunas zonas esa remoción fue intensa y había dado lugar a la pérdida de una parte del relleno en el momento en el que él mismo comenzó sus trabajos sistemáticos en el lugar. Los trabajos de Viñes, limitados a los años que transcurren entre 1928 y 1933, se alejaron del interior de la cavidad y se plantearon en las rampas de acceso a la cueva, llevándose a cabo en las zonas NE y SE de la misma. Así como en la zona s, donde localizó la existencia de una galería que se propuso excavar, aun cuando no llegara a cumplir más que parcialmente este objetivo.

La naturaleza del sedimento, de carácter limo-arenoso, poco consolidado y fácilmente erosionable con el mero tránsito por la superficie de la cueva, parece que había dado lugar, ya en las fechas en las que Viñes se hizo cargo de sus excavaciones, a importantes pérdidas del relleno en la zona interior de la cavidad, tal y como se desprende de la documentación fotográfica aportada (Viñes, 1942: fig. в). Los términos en los que se refiere a la zona interior de la cavidad, cuando en la nota publicada en 1928 da cuenta de los resultados obtenidos en la primera campaña practicada en el yacimiento, son suficientemente explícitos: "Presumí desde el primer momento que nada nuevo se ofrecería en el yacimiento del interior de la cueva, sino el confirmarme en su profunda remoción y desaparición en gran parte, pues su nivel primitivo ha bajado más de dos metros, y me lancé a explorar la rampa que da acceso a aquélla" (p. 2).

La ausencia de mayor detalle de la posición estratigráfica de los materiales recuperados en esos trabajos que la de su adscripción a una serie de paquetes o niveles identificados en la ladera, y la pérdida de gran parte de la documentación como consecuencia de las circunstancias violentas que acompańaron la muerte de este investigador, explican que años después, ya entrada la década de los años cuarenta del pasado siglo, Jordá señalara la existencia de serias dificultades para la adecuada identificación e interpretación de los materiales correspondientes a esas excavaciones.

Aunque no es el objetivo de estas líneas el analizar ni la propuesta estratigráfica efectuada por este autor ni la clasificación del material, sí que queremos llamar la atención sobre la existencia en las láminas del trabajo de Jordá de algunos materiales que apuntan claramente a la existencia de niveles del Paleolítico Superior mezclados con los del 
Paleolítico Medio. Algo que el mismo Viñes señaló al referirse al Nivel A, o superior, de su secuencia, al indicar que "por las hojas que se encuentran en él y más clara manifestación de la industria del hueso, bien pudiera incluirse en otra cultura, tal vez un Capsiense inferior" (Viñes, 1942: 12).

El inicio de la actividad de campo de Jordá en Cova Negra estuvo acompañado del estudio de los materiales recuperados por Viñes, publicando en 1945 una síntesis de la industria lítica procedente de las excavaciones de este último y en posteriores trabajos una propuesta actualizada de la seriación del relleno en la que se incorporaba ya el resultado de sus propias excavaciones.

En relación con el tema que nos ocupa, entre los materiales de los Niveles в y a de Viñes, Jordá da cuenta de algunas piezas que apuntan con claridad al Paleolítico Superior. Así, en el Nivel b, para el que propone una posición tardía en la secuencia musteriense, señala "ciertos tipos que preludian piezas y técnicas del Paleolítico Superior” (Jordá, 1945: 22). Destacan al respecto una serie de piezas cuyos dibujos aparecen recogidos en su trabajo: en primer lugar, por su claro componente laminar, la pieza $n .^{\circ}$ 7 de la fig. 9 de la citada publicación, que clasifica como un cuchillo y cuya fotografía incluimos en nuestra Fig. 8, n. ${ }^{\circ} 1$; seguidamente las piezas n. ${ }^{\text {os }} 11$ y 12 de esa misma figura, cuya morfología indica claramente que estamos ante un núcleo de láminas/ laminitas y un producto de acondicionamiento de un núcleo de marcado componente microlaminar, piezas que el autor clasifica como raspadores de tipo cónico; y, finalmente, la pieza número 8, que clasifica como un raspador. En cuanto al Nivel A, que se califica de carácter "anómalo y confuso", con materiales derivados del nivel anterior, es posible identificar también algunas piezas que parecen propias del Paleolítico Superior, pero en un contexto dominado por el material del Paleolítico Medio: la pieza n. ${ }^{\circ} 15$ de su fig. 10, que de nuevo parece un núcleo laminar, en este caso de carácter piramidal, que se clasifica como un raspador, y la pieza n. ${ }^{\circ} 5$ de su fig. 11 , cuyo retoque paralelo cubriente recuerda claramente al Solutrense. Esta pieza, analizada en el contexto de las comparaciones del Musteriense de la vertiente mediterránea con el del norte de África, sugirió en aquellas fechas a Jordá la técnica esbaikiense, de igual manera que la morfología proximal de algunas piezas le recordaron los pedúnculos propios del material del Ateriense. Idea que volvió a formular en 1953, en la publicación dedicada a dar cuenta de los resultados obtenidos en las excavaciones efectuadas en la cavidad hasta esa fecha. En los dos casos, se trata de comparaciones forzadas, especialmente en lo que se refiere a la pedunculación indicada en algunas piezas de los Niveles в y A, pues las piezas caracterizadas como tales carecen del sustento morfotipológico necesario para que puedan ser consideradas como de base pedunculada. Estas circunstancias explican que en poco tiempo las sugerencias de relación norteafricana fueran dejadas de lado (Jordá, 1956). Sin embargo, hasta esas fechas el peso del africanismo, resultante de los trabajos de Obermaier y su asignación al Capsiense de las industrias del Paleolítico Superior en la región mediterránea ibérica, y de la comparación entre Ateriense y Solutrense formulada por Caton-Thompson, tuvieron una profunda repercusión en la investigación.

Fueron los materiales reseńados los que motivaron la consideración de "que el Nivel a podría constituir, dentro del área levantina, una etapa que cronológicamente se correspondería con el auriñaciense inferior” (Jordá, 1945: 29). Una idea que volvió a plantear cuando contaba ya con los resultados de sus propias excavaciones en el yacimiento (Jordá, 1953) y formuló con detalle al comparar la secuencia de este yacimiento con la de Gorham's Cave (Jordá, 1956). En esta ocasión expresada en términos de la convivencia en el Nivel a de Cova Negra del Musteriense evolucionado y del Aurińaciense.

La reducida información sobre el relleno estratigráfico y la ausencia de cortes y fotografías de detalle de los niveles superiores en las excavaciones de Viñes y de Jordá constituyen un serio impedimento para una más ajustada valoración de la parte superior de la secuencia, así como del alcance que el revuelto superficial pudo tener en los diferentes espacios excavados y en la explicación del material del $\mathrm{Pa}$ leolítico Superior hasta ahora comentado. Sólo las excavaciones de los ańos ochenta y especialmente la actualmente en curso han permitido comprobar la potencia y el alcance del revuelto que corona la 


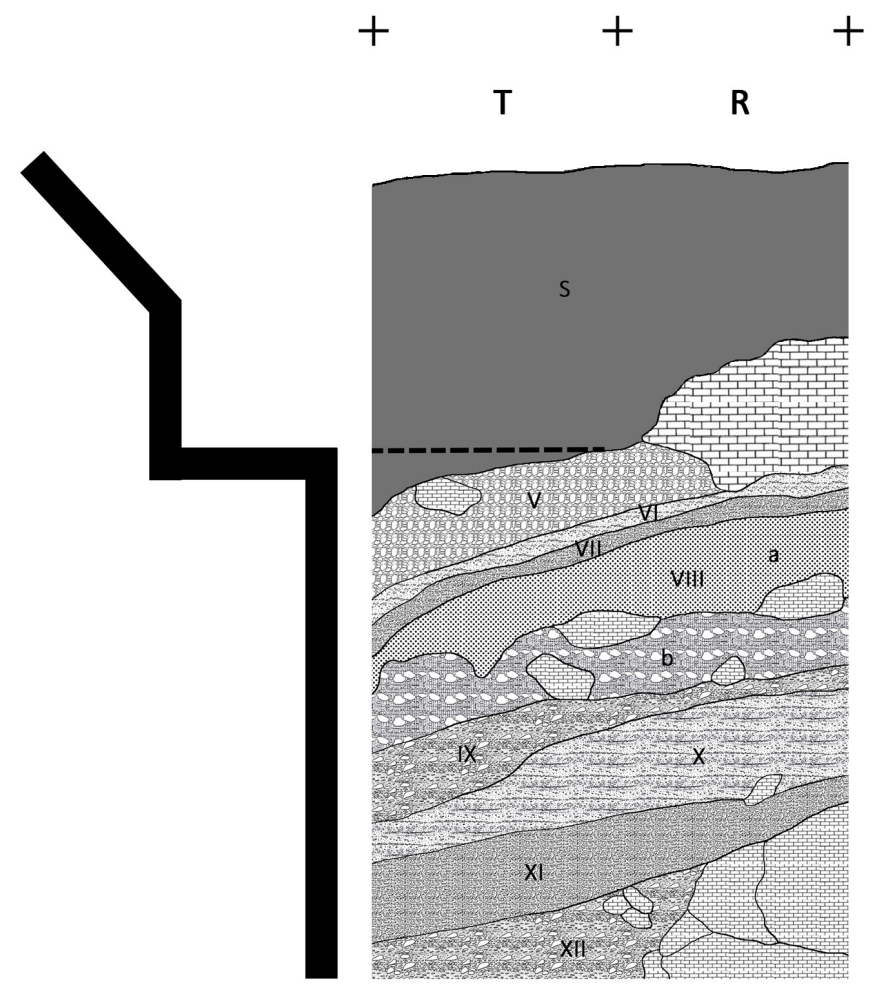

Fig. 2. Perfil frontal proximal del sector s (campaña 2016); con linea discontinua se marca el retroceso del perfil, tras la excavación del nivel superficial revuelto. Este escalonamiento estuvo motivado por el carácter poco consolidado e inestable del nivel superficial.

secuencia estratigráfica en la parte Sur de la cavidad. Se trata de un nivel de color marrón-grisáceo claro,

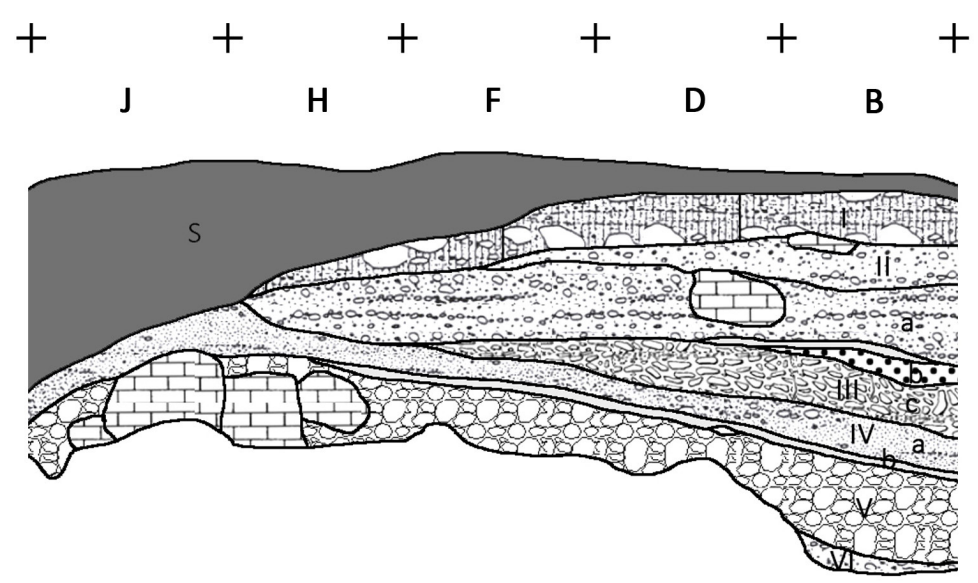

Fig. 3. Dibujo del perfil frontal proximal del Sector O. El Nivel Superficial erosiona progresivamente los paquetes in situ a medida que avanza hacia la zona sagital derecha. suelto y aspecto polvoriento, masivo y en contacto neto con las unidades sobre las que reposa (Fig. 2). Engloba abundantes clastos de tamaño medio y pequeño, y en algunas zonas parece algo más compactado, pero sin cambiar su estructura. En el mismo, además de materiales del Paleolítico Medio y Superior, aparecen algunos objetos modernos que confirman su carácter alterado. La mezcla de materiales de clara afiliación leptolítica alcanza la base del paquete, así como los del Paleolítico Medio aparecen también en todo el paquete, indicando que, en su conjunto, se trata de un depósito resultante de la redeposición de niveles inicialmente separados. Su origen puede estar asociado tanto a un proceso de arroyada de notable capacidad de transporte, favorecida por la elevada inclinación de la pendiente como al resultado de alteraciones antrópicas postdeposicionales, dada la escasa consolidación general de los sedimentos en toda la secuencia conservada.

En los dos sectores en los que este paquete ha sido excavado, su base reposa sobre distintos niveles estratigráficos, lo que confirma su carácter erosivo. En el sector o (Fig. 3), en la zona próxima al eje sagital central de la cavidad, reposa sobre el Nivel I, caracterizado por la presencia de abundantes cantos y gravas angulosas, de buen tamaño y escasamente alteradas, englobadas en una matriz fina arenosa de color amarillento (60\%), de estructura masiva y potencia que no sobrepasa los 20-30 cm. A medida que se avanza hacia la pared sur el revuel to aumenta de potencia, y se apoya sucesivamente sobre los estratos II al IV. En el Sector s, en la parte más alejada de la pared, apoya sobre el Nivel v, de matriz amarilla arenosa, con abundantes cantos y gravas, de estructura masiva que incluye brechas carbonatadas sobre elementos angulosos, si bien en la zona más cercana a la pared la alteración ha llegado a afectar hasta el Nivel Ix. Por otra parte, la sucesión estratigráfica a partir del Nivel v es idéntica en los Sectores o y s.

Antes de analizar los materiales del Paleolítico Superior que han aparecido 
en este nivel revuelto, es posible ya anticipar que en la secuencia de Cova Negra no existe ningún nivel in situ que corresponda a un momento tardío del Paleolítico Medio, ni ningún nivel in situ del Paleolítico Superior inicial.

Las excavaciones actuales y la revisión de la macro- y microfauna de los niveles superiores conservados en posición primaria apuntan, como ya se ha indicado (Villaverde et al., 2014), a cronologías propias del Pleistoceno Medio final e inicio del Pleistoceno Superior. Resultan determinantes, al respecto, el tamaño de los restos de gamo, cuyas proporciones anatómicas se sitúan en el límite inferior de Dama dama geiselana; la presencia de tahr de dimensiones similares a las de Hemitragus cendrensis; la ausencia de Terricola duodecimcostatus y Microtus arvalis, especies bien documentadas en los yacimientos del Paleolítico Medio del Pleistoceno Superior regional, y la presencia de Microtus brecciensis del Nivel v para abajo, mientras que el Microtus cabrerae sólo aparece documentado en los paquetes IV y superiores, confirmando por sus medidas una posición antigua dentro del Pleistoceno Superior ${ }^{3}$. A la espera de los resultados de las dataciones de OSL y ESR en curso, y de que concluya el estudio completo de la microfauna recuperada en la columna estratigráfica sondeada en las dos últimas campańas en el corte sagital izquierdo del Sector o, basta señalar que en esa misma perspectiva cronológica apuntan las dataciones de TL obtenidas de sílex termoalterados en los Niveles ViII $(255 \pm 20$ ka y $206 \pm 23 \mathrm{ka})$ y v $(235$ $\pm 21 \mathrm{ka}$ ) (Fumanal y Villaverde, 2009).

\section{Revisión de los materiales del Paleolítico Superior de las excavaciones de Jordá y los nuevos trabajos de campo}

Aunque las excavaciones de Cova Negra llevadas a cabo por el sip bajo la dirección de Jordá y otros investigadores de la institución comprendieron un total de 4 campańas entre 1950 y 1956, los materiales y resultados quedaron en su mayor parte sin publicar, lo que propició, ya transcurridos algunos

3 Comunicación personal de P. M. Guillem. años de la finalización de los mismos, la necesidad de abordar un estudio tanto de los restos faunísticos como de los materiales líticos. El primer aspecto fue llevado a cabo por Pérez Ripoll (1977) y el segundo por Villaverde (1984). Las limitaciones de los dos trabajos fueron las que se asocian a la ordenación de unos materiales que procedían de diversos sectores, obtenidos mediante un sistema de excavación por capas artificiales de cierta potencia y de los que se ofrecía en los diarios de campo una reducida atención por los aspectos estratigráficos y por la correlación de profundidades entre los distintos sectores. Habida cuenta de que la disposición de la estratigrafía del yacimiento presenta una pronunciada pendiente de orientación NO-SE y que las capas artificiales de excavación, correspondientes a sectores de cierta extensión, tuvieron una disposición horizontal, cabe pensar que los materiales, lejos de corresponder a unidades estratigráfica definidas, corresponden a una mezcla de niveles cuya precisa entidad es difícil evaluar sin referencias precisas a la disposición y potencia de los respectivos niveles en cada uno de los mismos. Por otra parte, el nivel superficial revuelto, aunque se documenta en la parte superior de todos los sectores conservados, posee sólo elevada potencia en la parte sur de la cavidad y aumenta algo hacia la boca, lo que implica que la importancia de los materiales asociados al mismo debieron alcanzar sólo cierta relevancia en la excavación de los Sectores F, D y C. Insistimos en este aspecto, porque resulta de especial importancia no sólo para valorar la existencia de materiales del Paleolítico Superior, sino de los del Paleolítico Medio clásico que también se engloban en este nivel revuelto.

A juzgar por los datos obtenidos en las recientes campañas realizadas en Cova Negra, el nivel in situ más elevado de la secuencia, el I, parece corresponder a la fase inicial del Pleistoceno Superior, probablemente del MIs 5. La abundancia de materiales del Paleolítico Superior en el nivel superficial, revuelto, y su asociación a restos líticos del Paleolítico Medio, que apuntan a una cronología clásica o propia del MIs 4, sugieren que la ocupación del lugar continuó, aunque desconozcamos su exacta entidad, desde el MIS 5 hasta el mIs 2. Probablemente, en forma de 
unos paquetes del Paleolítico Medio relativamente importantes en cuanto a restos líticos y aportes faunísticos, tal y como se deduce de comparar la entidad de los restos arqueológicos recuperados en los niveles del Paleolítico Medio conservados en posición estratigráfica y los de este paquete revuelto, y unas ocupaciones reducidas y muy espaciadas durante el Paleolítico Superior, tal y como indica la entidad proporcional de evidencias líticas que se pueden asociar a estas cronologías.

Pero, antes de entrar en estas valoraciones, resulta oportuno dar cuenta de los materiales del Paleolítico Superior recuperados hasta la fecha en el yacimiento y, a partir de los mismos y su distribución espacial, intentar precisar algo más la entidad de esas ocupaciones y la cronología a la que remiten.

\subsection{Materiales del Paleolitico Superior en las excavaciones de los años cincuenta del s. XX}

Si centramos la atención en las capas superiores de las excavaciones llevadas a cabo esos años, que son en las que cabe suponer que pueden englobar materiales del nivel revuelto, lo cierto es que el número de piezas que podrían relacionarse con el Paleolítico Superior es muy escaso, tanto desde el punto de vista tecnológico como tipológico, y especialmente en relación al primer aspecto, ya que el segundo resulta siempre más difícil de establecer en relación con los soportes no laminares. Así, del total de 466 piezas clasificadas procedentes de los distintos sectores excavados en la cueva, podrían sólo relacionarse con seguridad a cronologías del Paleolítico Superior algunos raspadores, buriles, perforadores y piezas truncadas. En total no más de 22 piezas, que en algunos casos no es posible descartar que sean del Paleolítico Medio. Serían las menos dudosas un raspador y un buril atípico del Sector C; un raspador carenado, un buril atípico y un perforador atípico del Sector B; cuatro raspadores, uno de ellos atípico, tres buriles, dos diedros y uno plano, y un perforador del Sector E; un raspador y un perforador atípico del Sector F; y una pieza truncada del Sector J1. Para evaluar el alcance que supone este material, hemos recurrido a comparar

\begin{tabular}{|c|c|c|}
\hline NIVEL & ÍNDICE LAMINAR & GRUPO IV \\
\hline I & 5,4 & 4,9 \\
\hline II & 5,4 & 4,9 \\
\hline III & 5,4 & 7,1 \\
\hline
\end{tabular}

FIG. 4. Indice laminar y piezas del Grupo IV de los Niveles I-III.

los índices laminares y del Grupo iv del Nivel i y los correspondientes a los Niveles II y III (Fig. 4), que en principio no deberían haber sido afectados por la remoción. La comparación permite comprobar que no existen diferencias en el componente laminar de los tres niveles, y que el grupo del Paleolítico Superior no resulta anómalamente alto en el nivel superior revuelto. El reducido número de piezas del Paleolítico Superior identificado en el material de las excavaciones de los ańos cincuenta confirma que en la mayor parte de los sectores el nivel revuelto debió ser de poco espesor. Además, son los sectores situados en la zona más cercana a la Pared $s$ de la cavidad - - y E- los que presentan un mayor número de piezas atribuibles a este periodo.

Por tanto, la baja proporción de piezas del $\mathrm{Pa}$ leolítico Superior recuperadas esos años tiene que ver con la desigual potencia del nivel superficial -revuelto-, que sólo alcanza una considerable entidad en la zona inmediata a la Pared s, colmatando la prolongación de la cueva hacia esa dirección. Circunstancia que parece sugerir que los paquetes superiores fueron desmantelados y desplazados hacia esa zona, que debió actuar como espacio de recepción de acuerdo con la pendiente general que adquieren los estratos en todas las zonas excavadas ${ }^{4}$.

\footnotetext{
4 Solamente se observa un cambio de pendiente en la Zona N excavada en los años 1981 y 1982, y en este caso parece debida al hundimiento de una galería subterránea que provocó un disloque de la estratigrafía con pendiente hacia la pared norte de la cavidad. El relleno que con posterioridad niveló la zona no es de características similares al Nivel I hasta ahora descrito, pues engloba muy escaso material y algunas piezas de época moderna. Lo que sugiere que el proceso de hundimiento fue tardío y una vez desmantelada la secuencia superior del yacimiento, aquella que englobaba los niveles de los mis 4 a 2 .
} 


\subsection{Materiales del Paleolitico Superior en las excavaciones de los años ochenta del s. XX}

En el sector Oeste, en la zona que comprendían los Cuadros L, J y H/1', 1 y 2, una zona en la que el nivel superficial revuelto alcanzaba cierta potencia, se recogieron un total de 1.166 restos líticos. De estos, atendiendo a criterios tecnológicos, pudieron asignarse al Paleolítico Superior un total de 151 piezas $-12,95 \%$ del total-, de las cuales 29 fueron objeto de clasificación mediante la lista-tipo (Villaverde, 1984). El conjunto presenta tres raspadores simples, uno sobre lasca (Fig. 5 , n. $^{0} 1$ ) y otros dos sobre soporte laminar (Fig. 5, n. ${ }^{\text {s }}$ 2-3); un raspador doble (Fig. 5, n. ${ }^{\circ} 4$ ); dos raspadores sobre lasca u hoja retocada (Fig. 5, n. ${ }^{\circ}$ 5); cuatro raspadores carenados (Fig. 5, n. ${ }^{\text {os }} 6-9$ ); un raspador carenado atípico (Fig. 5, n. ${ }^{\circ}$ 10); un raspador-truncadura (Fig. 5, n. $\left.{ }^{\circ} 13\right)$; cinco buriles diedros de ángulo sobre fractura, en un par de casos en soporte laminar (Fig. 5, n. ${ }^{\circ} 11$ ); un buril sobre truncadura cóncava (Fig. 5 , n. $\left.{ }^{\circ} 12\right)$; un buril sobre truncadura convexa, un buril plano, dos microgravettes (Fig. 5, n. ${ }^{\text {os }} 14-15$ ); una punta escotada (Fig. 5, n. ${ }^{\circ}$ 16); una pieza con truncadura oblicua (Fig. 5, n. ${ }^{\circ} 17$ ); una pieza con retoques continuos en un borde; una pieza con retoques continuos en los dos bordes; una hoja aurińaciense (Fig. 5, n. ${ }^{\circ}$ 19), y una hojita de borde abatido rota o fragmento de microgravette (Fig. 5, n. ${ }^{\circ}$ 18). Material al que se sumó un pequeño pero interesante lote de industria ósea compuesto por un fragmento de punta de sección subcircular de asta (Fig. 5, n. ${ }^{\circ}$ 20); un fragmento de punta de hueso de sección triangular (Fig. 5, n. ${ }^{\circ} 21$ ); un fragmento medial de punta de hueso de sección subcircular, tendente a aplanada (Fig. 5, n. ${ }^{\circ}$ 22); una esquirla ósea retocada (Fig. 5 , n. $\left.{ }^{\circ} 24\right)$, y un fragmento de colorante.

Los trabajos de limpieza del nivel revuelto superficial llevados a cabo en distintos sectores de la cavidad con la finalidad de identificar los paquetes in situ que permitieran plantear nuevas excavaciones, junto a un dominio de materiales de clara adscripción al Paleolítico Medio -especialmente raederas-, proporcionaron también otros, menos numerosos, de tipología leptolítica. Así, en la zona correspondiente a la Galería Viñes, en la parte meridional de la cavidad, se recogieron algunas piezas que, de nuevo, se reparten entre el Paleolítico Medio y Superior. Se trata de tan sólo 21 piezas, de las que 7 pueden relacionarse con el Paleolítico Superior a partir de la tipología: dos raspadores simples (Fig. 5, n. ${ }^{\text {os }}$ 25-26); dos raspadores sobre lasca u hoja retocada (Fig. 5, n. ${ }^{\text {os }} 23$ y 31 ); un raspador carenado (Fig. 5, n. $\left.{ }^{\circ} 27\right)$; una pieza con escotadura distal y fractura (Fig. 5, n. ${ }^{\circ} 32$ ), y una hojita de borde abatido (Fig. 5, n. $\left.{ }^{\circ} 28\right)$.

En la zona correspondiente al Sector E, cuando se procedió a su limpieza, se recogieron también algunas piezas de tipología relacionable con este periodo: un raspador carenado (Fig. 5, n. ${ }^{\circ} 29$ ); un buril diedro de ángulo (Fig. 5, n. ${ }^{\circ}$ 30); una pieza de borde abatido; una punta escotada de reducido tamaño, ligeramente rota en su zona apical (Fig. 5, n. $\left.{ }^{\circ} 33\right)$, así como una concha perforada con restos de ocre (Fig. 5, n. $\left.{ }^{\circ} 34\right)$.

$\mathrm{Y}$, finalmente, en la zona correspondiente al Sector D aparecieron cinco piezas atribuibles al $\mathrm{Pa}$ leolítico Superior: un raspador simple, un raspador sobre lasca retocada, una hoja con truncadura recta y una hojita, posiblemente apuntada, de retoque abrupto. Y en el cuadro P-11 -Sector s-, se recogió un fragmento proximal de punta monobiselada, con decoración de líneas incisas paralelas inversas en el bisel (Fig. 5, n. ${ }^{\circ}$ 35).

\subsection{Materiales del Paleolitico Superior en las excavaciones de 2013 a 2016}

Como resultado de la preparación para su excavación del Sector $S$ de la cavidad, en los Cuadros R, $\mathrm{T}, \mathrm{v} / 9-13$ se excavó el nivel revuelto que englobaba desde materiales recientes hasta una abundante representación de restos líticos y óseos del Paleolítico Medio y Superior, así como algunos fragmentos óseos humanos, de clara morfología neandertal y en curso de estudio. El nivel revuelto, de color marrón grisáceo claro, estructura masiva y abundante fracción gruesa de tamaño medio y grande, alcanza en esa zona en torno al 1,30 $\mathrm{m}$ de potencia máxima, especialmente en torno a la banda de los $9 \mathrm{~m}$, y de manera muy particular a medida que se avanza en 

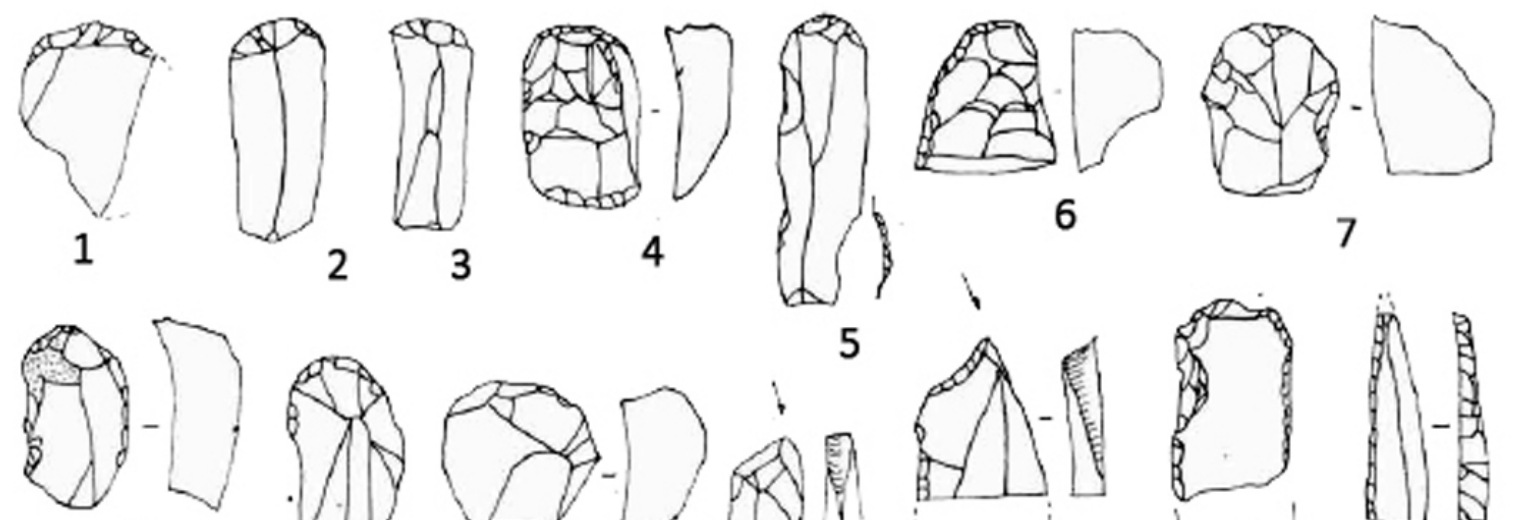

8
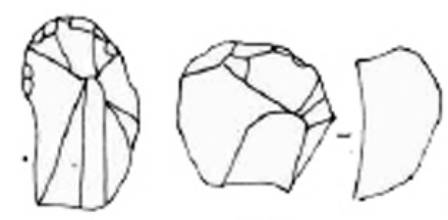

5
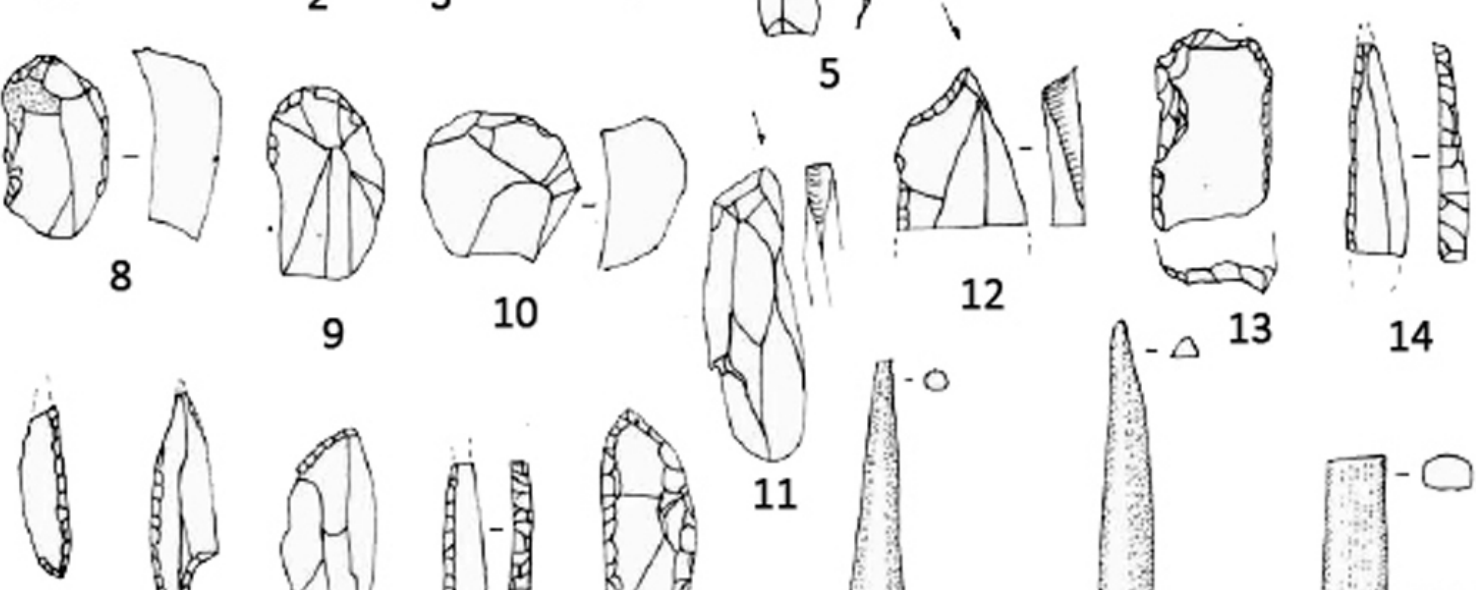

9

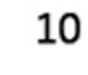

15
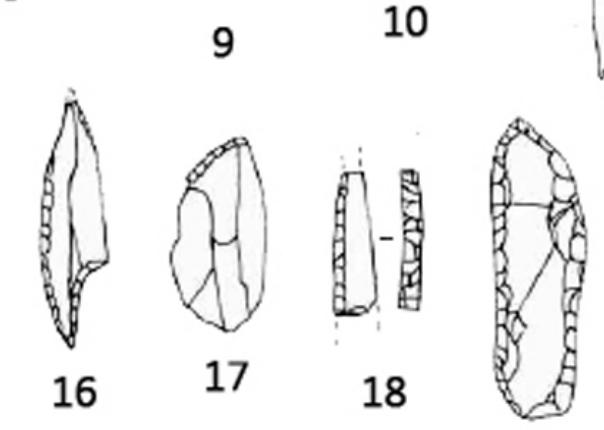

18

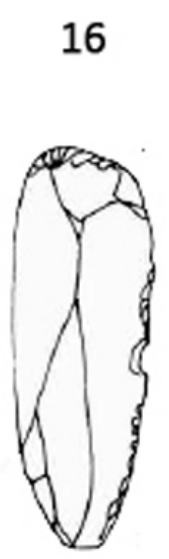

17
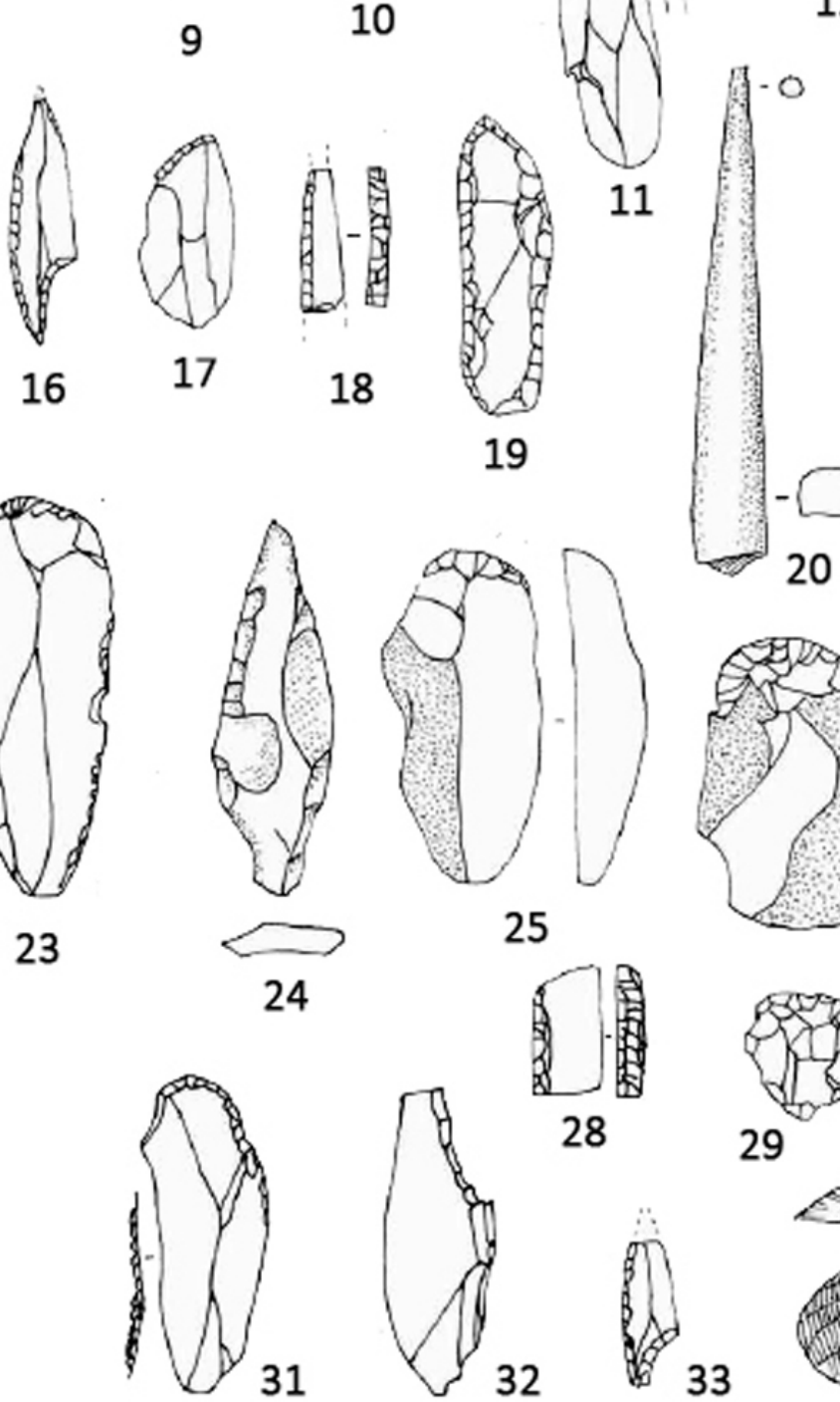

12

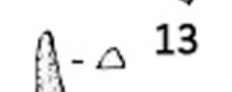

14

31

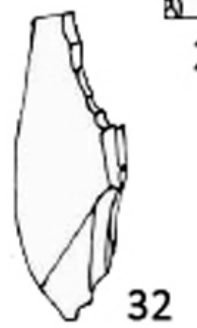

28
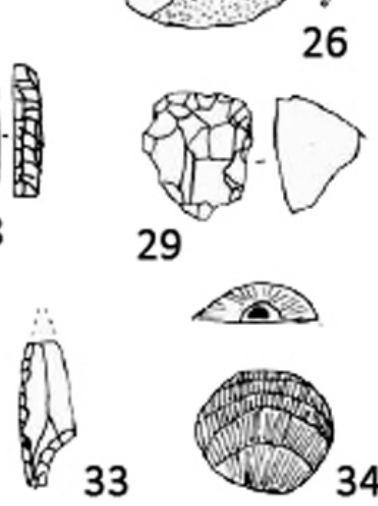

29

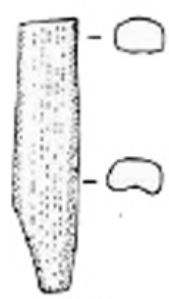

22
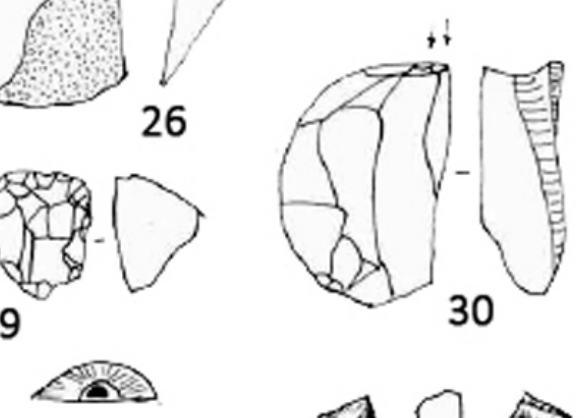

Fig. 5. Materiales adscritos al Paleolítico Superior procedentes de las campañas de los años 80 (según Villaverde, 1984, modificado). 

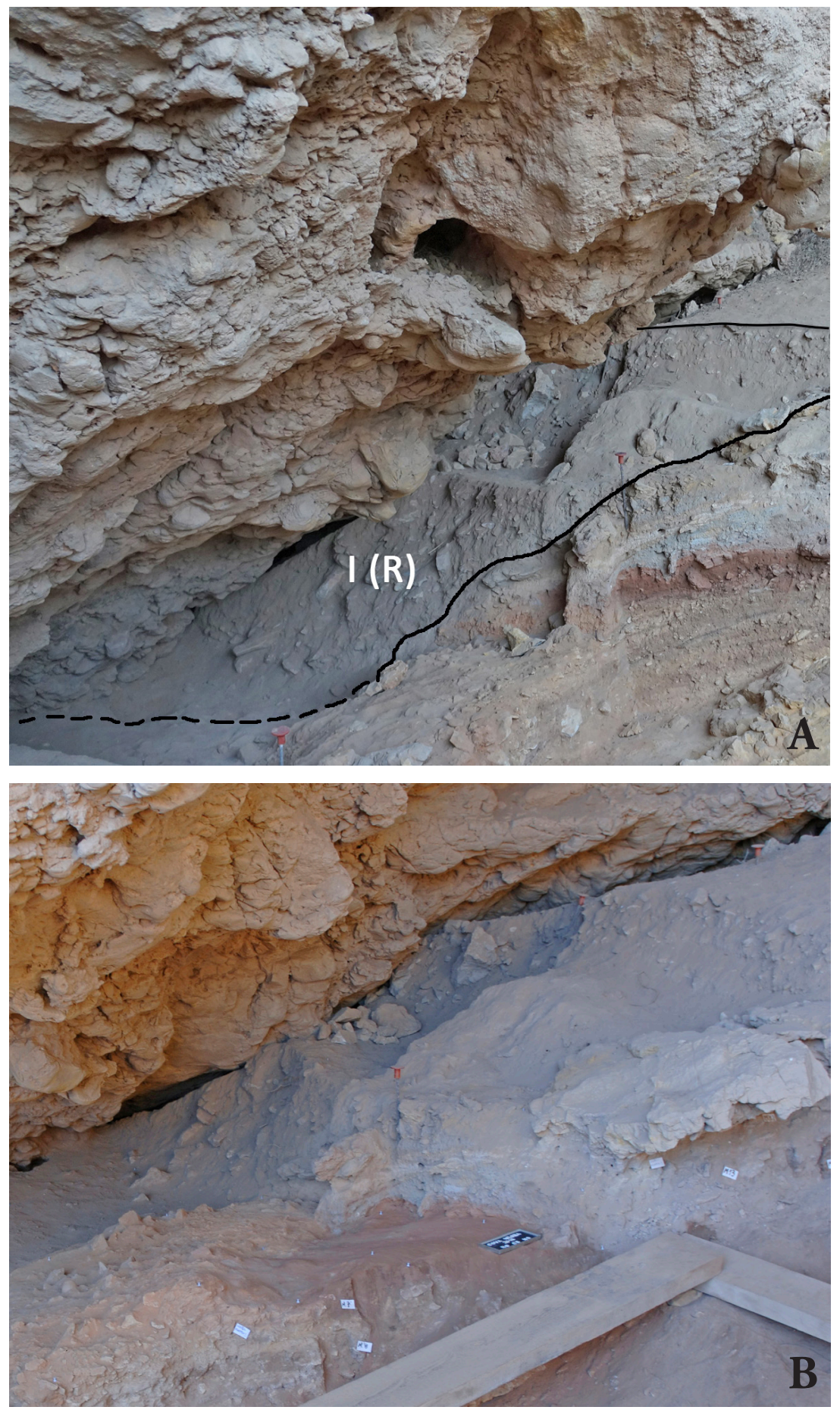

dirección a la pared s de la cavidad, cuyo desarrollo queda interrumpido por la colmatación de este relleno (Fig. 6).

El material recuperado en ese paquete asciende a 1.030 piezas, de las que 235 pueden atribuirse al Paleolítico Superior, lo que supone un 22,81\%. El resto posee las características técnicas y tipológicas propias del Paleolítico Medio, con abundante representación de raederas y una cierta presencia de la talla Levallois. La comparación entre la importancia del conjunto atribuido al $\mathrm{Pa}$ leolítico Superior de esta zona y la del Sector o, excavada en los años noventa, resulta claramente indicativa de que a mayor espesor del nivel revuelto y a su asociación con las zonas de colmatación de la cavidad en su pared sur, mayor es la evidencia arqueológica que remite a este periodo, indicando el desmantelamiento y erosión de los paquetes superiores en el resto de la superficie y su redeposición en la zona indicada, aquella en la que converge el buzamiento general de la estratigrafía.

El conjunto que relacionamos con el Paleolítico Superior está formado por 8 núcleos, 149 productos del lascado, 77 piezas retocadas y un percutor. Puesto que la selección se ha realizado atendiendo a criterios tecnológicos y tipológicos, se

Fig. 6. Imágenes del inicio del levantamiento del Nivel IX: A) vista general del Sector S, con la zona excavada desde 2013 a 2016; se indica el contacto entre el nivel superficial (revuelto) y los niveles in situ. En la zona izquierda, la más cercana a la pared, la base todavía corresponde al revuelto. B) detalle del proceso de excavación del Nivel VIII B (campaña 2015); el alcance y morfología del nivel revuelto se observan perfectamente en la zona que colmata el desarrollo de la cavidad hacia la Zonas. 

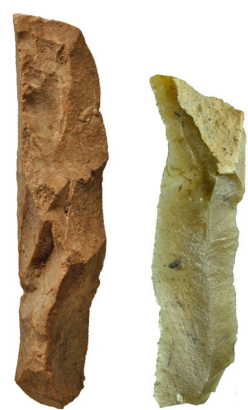

1
2
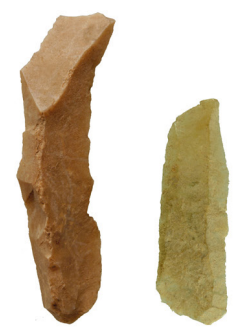

3
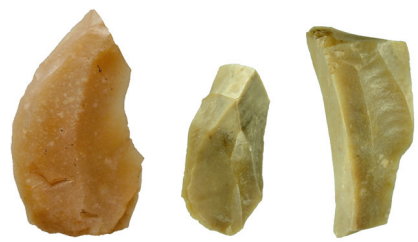

11
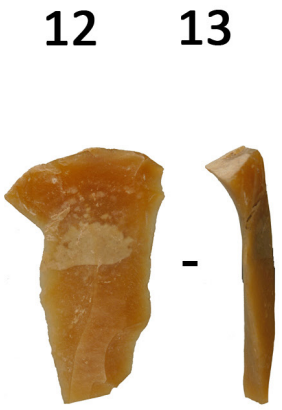

24
4

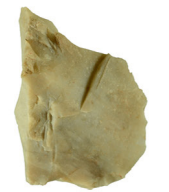

14

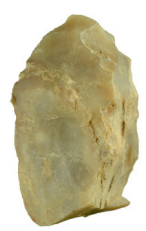

25

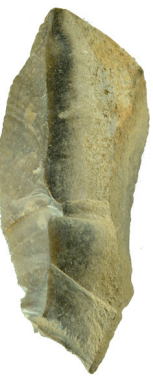

5

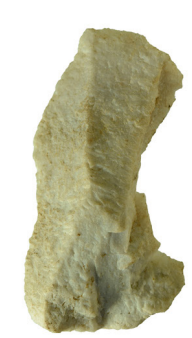

6

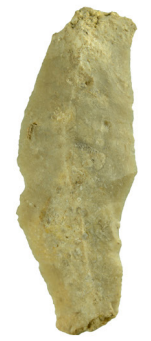

7

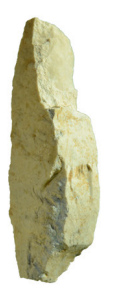

8

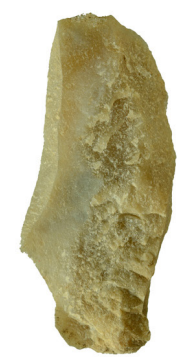

9

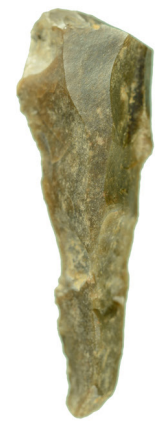

10

Fig. 7. Soportes documentados: 1, 3, 10, 28 y 30) semicrestas; 2, 4-9, 24 y 29) hojas; 11-13 y 15) flancos laterales de núcleo; 14) semitableta; 16-17 y 19-23) hojitas; 18 y 27) golpes de buril; 25) cresta; 26) arista de núcleo.

sobreentiende que la mayor parte de las piezas se relacionan con la talla laminar: 70 hojas y fragmentos de hoja, 29 lascas laminares, 77 hojitas y fragmentos de hojita, 1 cresta, 12 semicrestas, 2 semitabletas y 7 golpes de buril (Fig. 7). Aunque alguna de las piezas de esta relación pudiera corresponder al Paleolítico Medio, el bajo índice laminar habitual en el Paleolítico Medio regional, y en particular en Cova Negra, permite deducir que no debe tratarse de una parte sustancial de este material seleccionado.

En el caso de los núcleos (Fig. 8), dominan los laminares y microlaminares unipolares, y cabe resaltar la presencia de uno ortogonal, de planos secantes y un buril nucleiforme, con extracciones en los dos lados pequeños. En dos casos el inicio de la talla parte de crestas. La dificultad de adscribir algunos núcleos de lascas al Paleolítico Superior explica que hayamos preferido no incluirlos en esta relación, cuya finalidad no es otra que señalar la existencia de procesos propios de la talla laminar.

En los productos del lascado dominan los talones lisos -94 casos-, con 3 corticales, 7 facetados, 15 lineales, 5 puntiformes, 3 diedros, 20 suprimidos y 28 rotos.

Al considerar la cadena operativa, 6 piezas corresponden a la fase de inicio de la explotación y 192 a plena explotación, con presencia de 27 productos de acondicionamiento del núcleo, algunos 

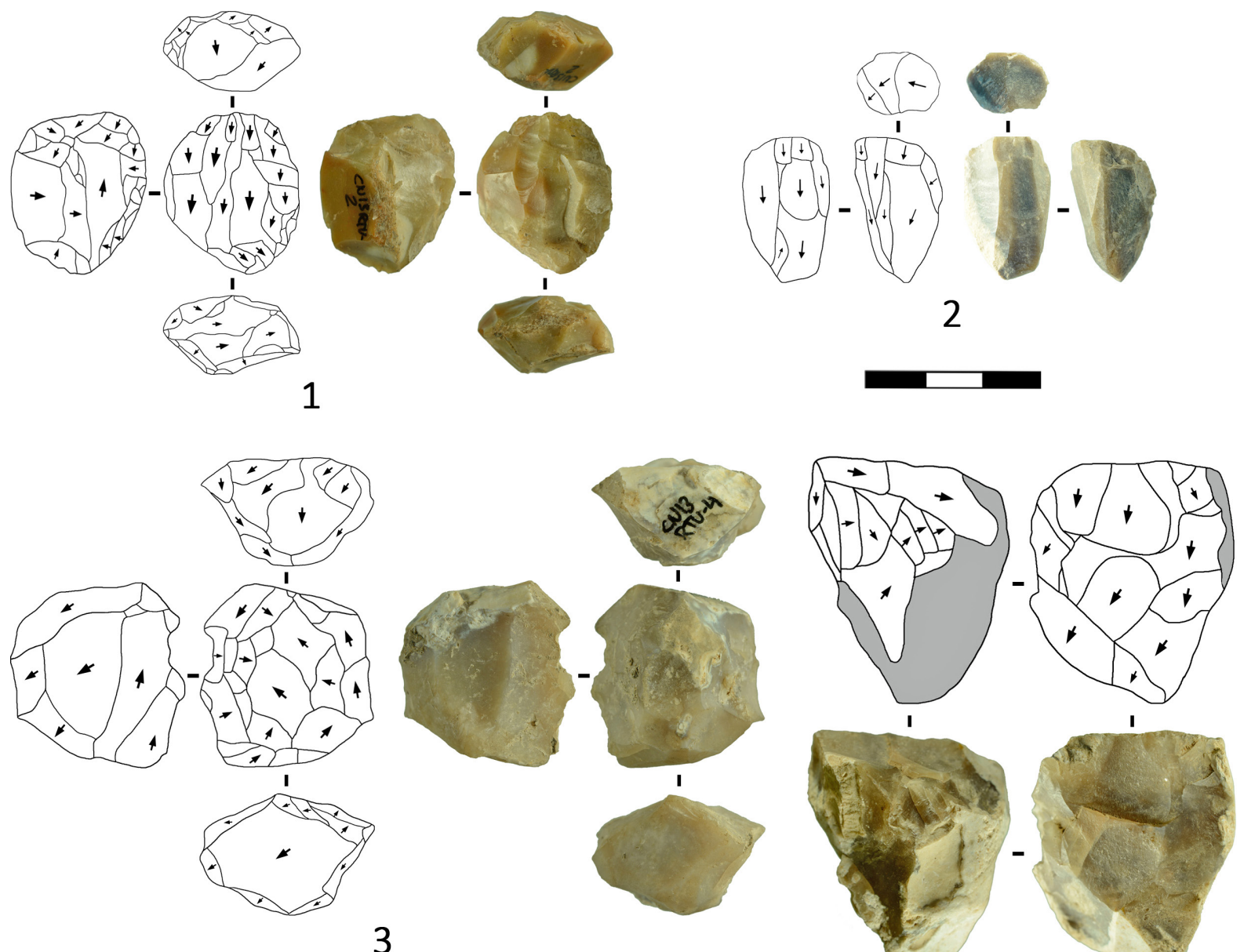

3
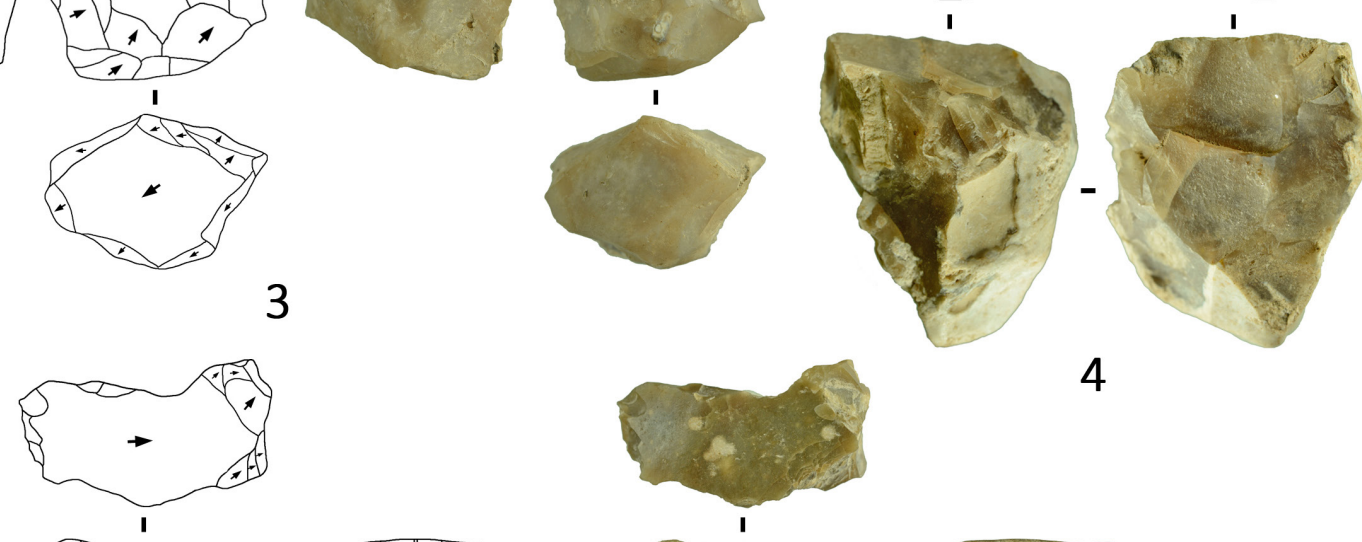

4
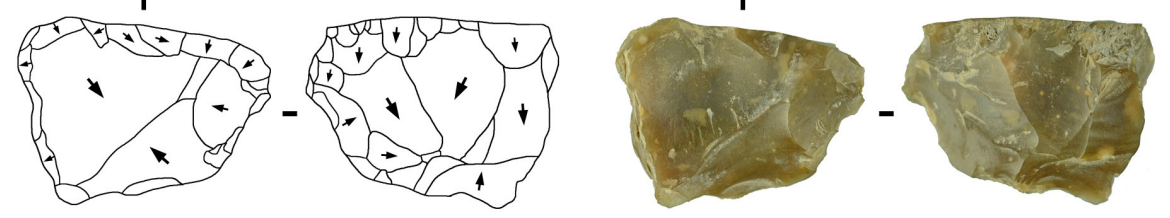

5
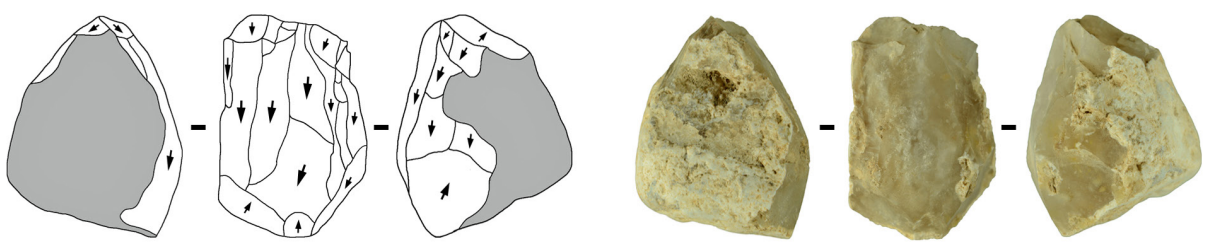

6

Fig. 8. Núcleos laminares unipolares. 


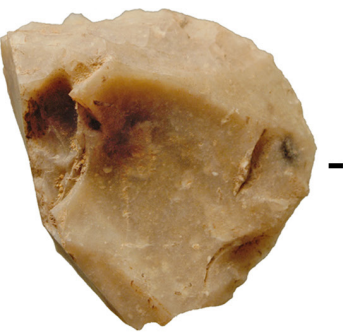

1

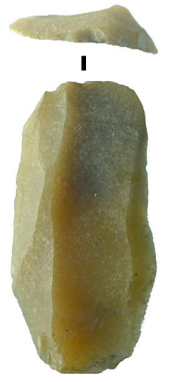

7

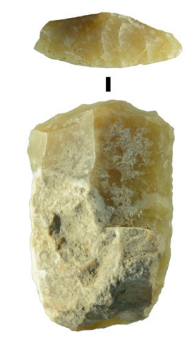

8

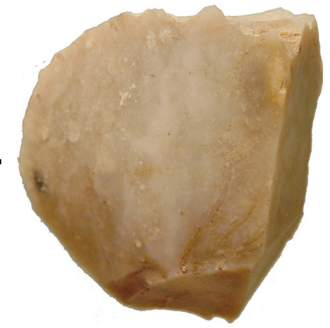

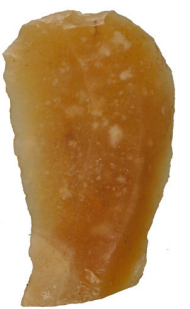

2

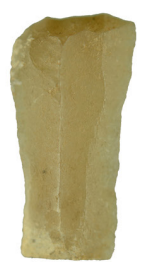

3

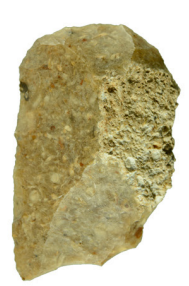

4

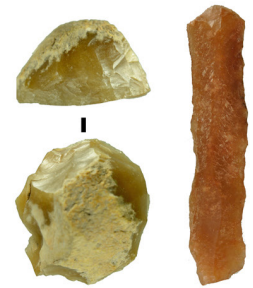

56

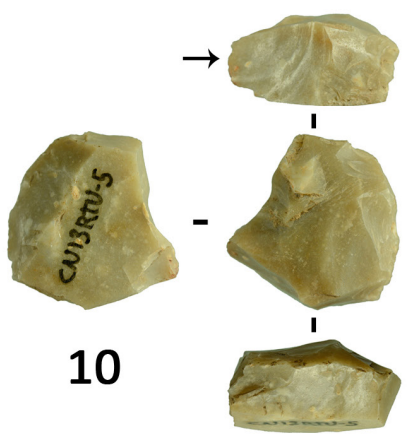

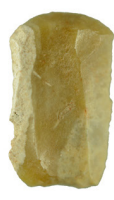

9

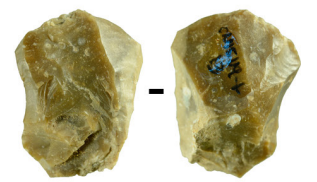

14

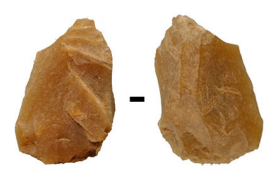

15

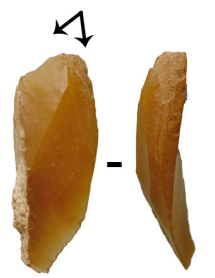

18

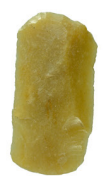

19

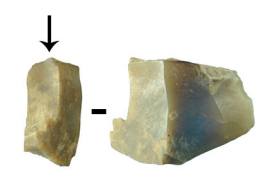

16

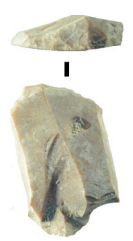

20

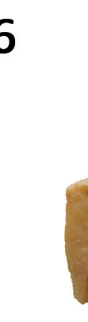

21

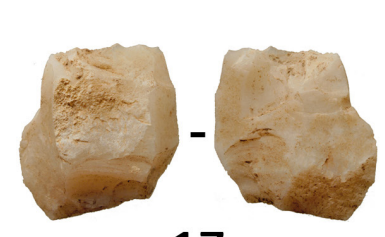

17

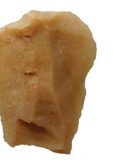

21

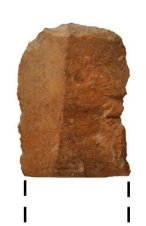

11
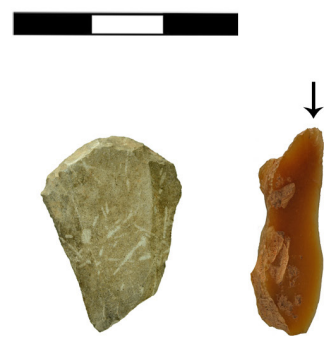

12

13

FIG. 9. Material retocado procedente de las campañas de 2013 a 2016 (raspadores, buriles, piezas astilladas y otros).

transformados mediante retoque. Sólo 3 piezas no permiten asignación a la fase de explotación. Este número especialmente bajo es consecuencia del proceso de identificación del material, ya que sólo los soportes bien conservados han sido identificados como propios del Paleolítico Superior.

El conjunto, por lo que respecta a las materias primas empleadas, presenta un dominio importante del sílex de tipo Serreta -128 piezas- y una presencia nada despreciable de sílex de tipo Mariola
-54 piezas-. El resto del material se compone de 31 piezas de materia prima indeterminada, 2 piezas de sílex negro translúcido, 1 pieza de sílex azul con inclusiones, 9 de sílex marrón opaco y 8 de sílex calizo blanco, además de 1 cuarcita y 1 caliza.

Es evidente, dado que el conjunto estudiado procede de una selección de materiales mezclados del Paleolítico Medio y Superior, que ni la valoración de la proporción de la técnica laminar ni la representación de las distintas fases de la cadena 
operativa resultan significativas a efectos de establecer comparaciones o para la caracterización industrial del material. Por ello, al igual que en los apartados anteriores, limitaremos el estudio a la valoración de los principales grupos tipológicos.
El conjunto retocado, formado como se indicó por 77 piezas, presenta la siguiente clasificación: 9 raspadores simples sobre hoja u hojita (Fig. 9, n. ${ }^{\text {os }}$ 2, 3, 7, 9, 19, 21 y 23), 2 raspadores simples sobre lasca (Fig. 9, n. ${ }^{\text {os }} 12$ y 20), un raspador doble (Fig. 9,

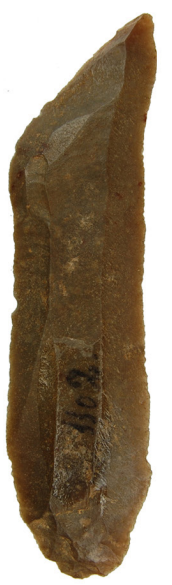

1

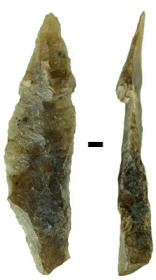

5
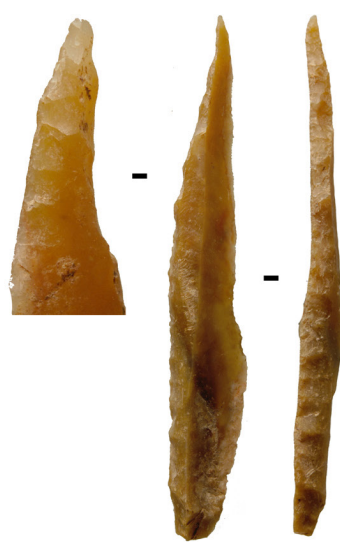

2

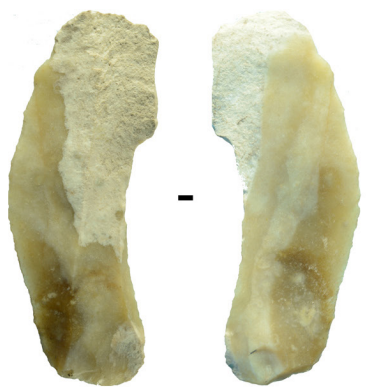

3

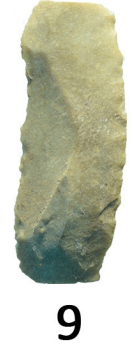

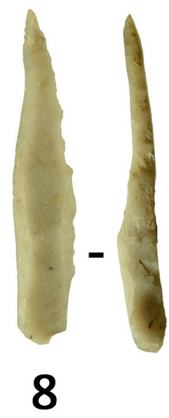

7

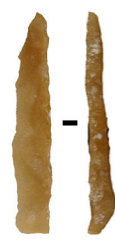

7
6

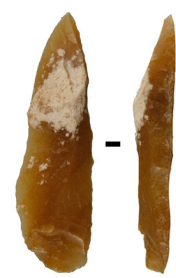

6

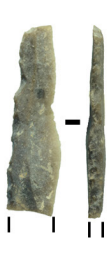

14

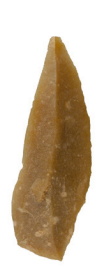

15

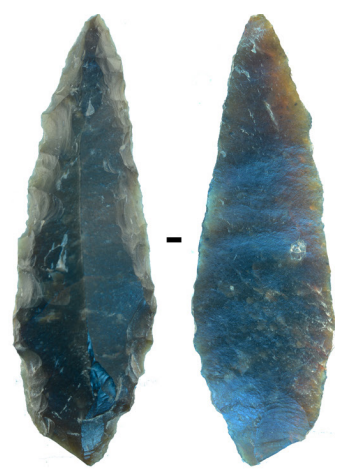

4
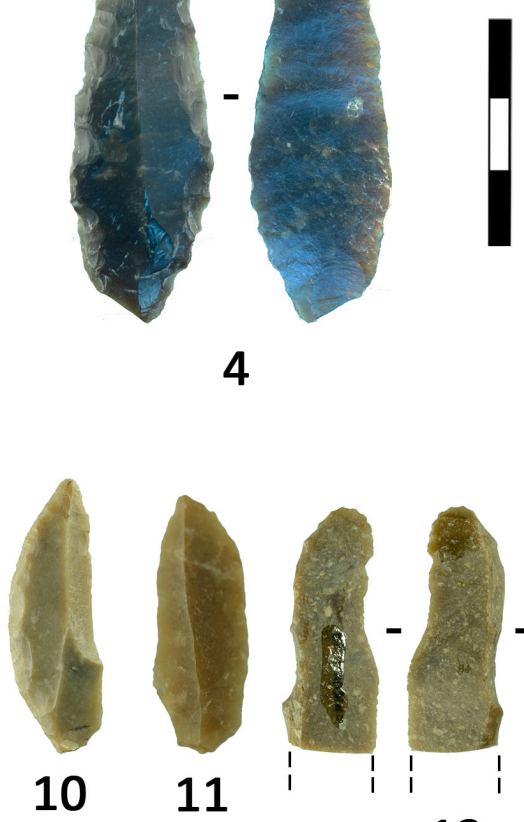

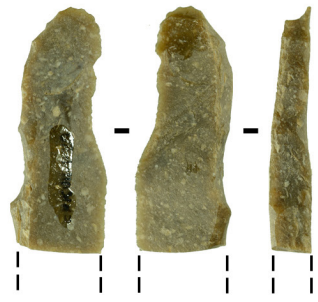

12

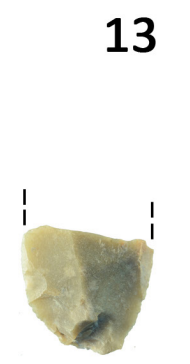

20

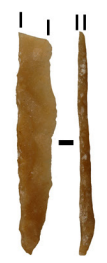

$21 \quad 22$

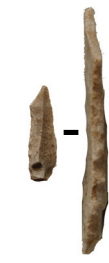

23

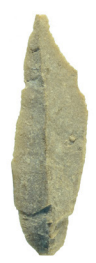

24

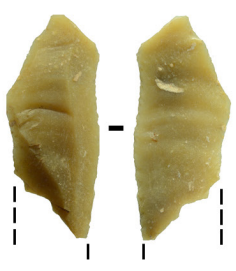

16
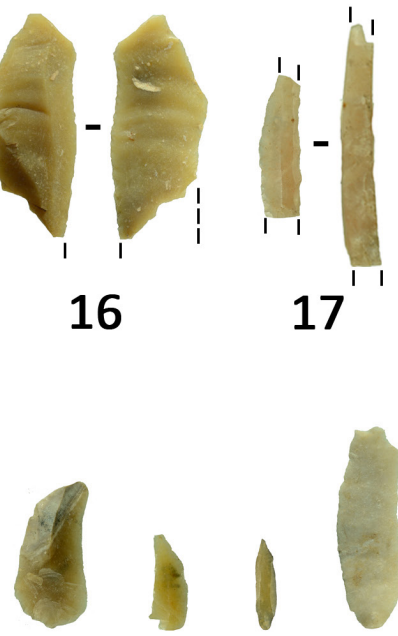

17

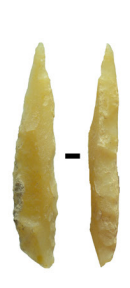

18

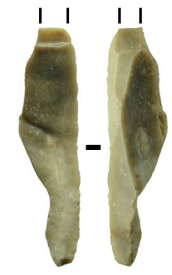

19

FIG. 10. Material retocado (dorsos y puntas) procedente de las campañas de 2013 a 2016. 
n. $\left.{ }^{\circ} 8\right)$, dos raspadores sobre hoja u hojita retocada (Fig. 9 n. ${ }^{\text {ss }} 6$ y 11), 3 raspadores sobre lasca retocada (Fig. 9, n. ${ }^{\text {os }} 1,4$ y 22), y un raspador nucleiforme (Fig. 10, n. ${ }^{\circ}$ ); un raspador-truncadura, sobre soporte laminar; tres buriles simples de ángulo sobre fractura (Fig. 9, n. ${ }^{\text {s }} 13$ y 16), un buril diedro desviado (Fig. 9 n. ${ }^{\circ}$ 18) y un buril nucleiforme (Fig. 9, n. $\left.{ }^{\circ} 10\right)$; una hoja con truncadura proximal; dos rasquetas (Fig. 9, n. ${ }^{\circ}$ 13), 3 puntas de cara plana (Fig. 10, n. ${ }^{\text {os }} 4,10$ y 20), una de ellas fracturada en su parte distal, 7 piezas astilladas (Fig. 9, n. ${ }^{\text {ss }} 14,15$ y 17 ), una hoja apuntada mediante retoque inverso, que aprovecha una cresta y presenta dos fracturas en lengüeta en la parte proximal (Fig. 10, n. ${ }^{\circ}$ 19), una muesca, 5 puntas de la Gravette (Fig. 10, n. ${ }^{\text {os }} 2$, 5-7 y 8), una rota en su extremo distal, una punta tipo Cendres (Fig. 10 n. ${ }^{\mathrm{o}} 15$ ) y 2 microgravettes (Fig. 10, n. ${ }^{\text {os }} 17$ 18) y 3 hojas con retoque alternante (Fig. $10, n^{\circ} 3$, 9 y 16); en el utillaje microlaminar 7 laminitas de dorso (Fig. 10, n. ${ }^{\text {s }} 12,14,21-23$ y 29), 9 laminitas

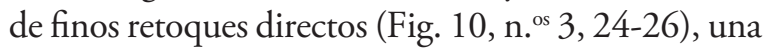
laminita con finos retoques inversos (Fig. 10, n. ${ }^{\circ} 28$ ), 5 fragmentos inclasificables y 8 piezas con retoques marginales o de uso (Fig. 10, n. ${ }^{\text {os }} 1,11$ y 27 ).

\section{Valoración del conjunto de los materiales y su interés en la interpretación de la ocupación humana de Cova Negra}

El principal interés del material lítico hasta ahora analizado estriba en confirmar que en el yacimiento se produjeron ocupaciones vinculadas al Paleolítico Superior. Por otra parte, los restos no se limitan a productos acabados, vinculados a la fase de uso y abandono, y la variedad tipológica remite a distintas etapas del Paleolítico Superior, por lo que las ocupaciones se repitieron en distintas etapas y debieron estar asociadas a distintos niveles. Al considerar estos aspectos, resulta evidente que cualquier intento de profundizar en los rasgos tecnológicos o, incluso, en los tipológicos, resulta desaconsejable. Además, el número de piezas y la amplitud cronológica a la que remiten los distintos materiales incitan a pensar que las ocupaciones fueron de poca entidad y relativamente esporádicas. De otra forma, las cuantificaciones de soportes y piezas retocadas serían muy superiores a las descritas.

La atribución cultural de estos materiales ha de hacerse a la luz de lo visto en los apartados anteriores, pues resulta obvio, por una parte, que durante el Solutrense evolucionado la cavidad fue ocupada, tal y como lo indican las puntas escotadas y la pieza con escotadura distal que proceden de las campañas de los años 90. La asociación de estas dos piezas es típica de momentos avanzados de este tecno-complejo, especialmente si consideramos el reducido tamaño de una de las piezas (Fig. 5, n.o 33) (Fullola, 1979; Fortea et al., 1983; Villaverde y Peña, 1981). A esos materiales se suman ahora las tres puntas de cara plana citadas en el apartado anterior, así como la pieza de retoque plano recuperada en las campañas de Viñes, lo que sugeriría la existencia de materiales que corresponderían a etapas solutrenses más antiguas. $\mathrm{Al}$ respecto, los datos obtenidos en los niveles solutrenses de Parpalló (Pericot, 1942) y Malladetes (Fortea y Jordá, 1976) indican que en las fases avanzadas del Solutrense evolucionado o Solútreo-Gravetiense las puntas de cara plana y las piezas foliáceas no alcanzan valores significativos. También es clara, especialmente a partir de los materiales de los años 2013-2016, la existencia de materiales del Gravetiense, especialmente si tenemos en cuenta las magníficas puntas de La Gravette sacadas a la luz estos últimos años. A esa misma cronología o al Solutrense evolucionado cabría atribuir las microgravettes y algunas piezas de dorso, pues es sabido que estos materiales se encuentran representados en las industrias mediterráneas de ambos periodos. En cuanto a las piezas astilladas, su documentación a lo largo de toda la secuencia del Paleolítico Superior regional impide asignarlas a ningún periodo específico, si bien se trata de un tipo que alcanza valores elevados en los contextos gravetienses hasta ahora estudiados en la región (De la Peña y Vega, 2013). Por otra parte, el elevado componente de dorsos, la tipología de alguno de los buriles (planos, diedros y sobre truncadura) y la presencia de algunas piezas truncadas resultan sumamente coherentes con la idea de que durante el Gravetiense la cavidad registró presencia humana. Menos clara resulta la documentación del Magdaleniense, pues las rasquetas y los elementos microlaminares no 
resultan cuantitativamente determinantes, ya que se encuentran ampliamente documentados en otros periodos del Paleolítico Superior regional, si bien algunos raspadores de reducido tamaño resultan sugerentes de la presencia en el yacimiento de algunos materiales correspondientes a este periodo. En esa misma línea están las pocas piezas de industria ósea documentadas, especialmente el fragmento basal de punta monobiselada decorada. Finalmente, algunos raspadores espesos y una hoja aurińaciense podrían corresponder al Auriñaciense, pero en este caso con muy poca seguridad, porque el número de piezas es reducido y es imposible establecer la cronología de estas piezas (Fig. 11).

\begin{tabular}{|c|c|c|c|c|c|c|}
\hline & AÑOs 50 & $\begin{array}{l}\text { SECTOR O } \\
\text { (AÑOS 90) }\end{array}$ & $\begin{array}{l}\text { SECTOR S } \\
\text { (AÑOS 90) }\end{array}$ & $\begin{array}{l}\text { SECTOR E } \\
\text { (AÑOS 90) }\end{array}$ & 2013-16 & TOTAL \\
\hline Raspadores & 7 & 11 & 4 & 2 & 19 & 43 \\
\hline Compuestos & - & 1 & - & - & - & 1 \\
\hline Perforadores & 3 & - & - & - & - & 3 \\
\hline Buriles & 5 & 8 & - & 1 & 1 & 15 \\
\hline Dorsos & - & 3 & - & - & 9 & 12 \\
\hline Truncaduras & 1 & - & - & - & 1 & 2 \\
\hline Piezas retocadas & - & 2 & - & - & - & 2 \\
\hline Solutrense & - & 1 & 1 & - & 3 & 5 \\
\hline Varios & - & 1 & - & - & 3 & 4 \\
\hline Microlaminar & - & 1 & 1 & 1 & 17 & 20 \\
\hline Otros & - & - & - & - & 5 & 5 \\
\hline Retoques de uso & - & - & - & - & 8 & 8 \\
\hline Total & 16 & 28 & 6 & 4 & 66 & 120 \\
\hline
\end{tabular}

FIG. 11. Atribución tipológica de los materiales líticos procedentes de las campañas desarrolladas en los años 50, 90 y en 20132016.

A la vista de lo comentado no es fácil evaluar si alguno de los periodos enunciados pudo estar asociado a una mayor entidad de la ocupación. La abundancia de piezas de dorso y el carácter general de la industria sólo resultan coherentes con dos fases de la secuencia regional: el Gravetiense y el Solutrense evolucionado. Sin embargo, el reducido número de puntas escotadas no parece redundar en la idea de que sea ese precisamente un momento de importante ocupación en Cova Negra, y la posibilidad de que una buena parte de los materiales pueda remitir al Gravetiense no entra en contradicción con la entidad que esta fase ha alcanzado en los últimos ańos, lo que apunta a que es un periodo de clara consolidación de la ocupación humana a nivel regional (Fullola et al., 2007).

Puesto que entre las 132 piezas que en total hemos atribuido al Paleolítico Superior se incluyen materiales que indican la existencia de diversos periodos, no parece oportuno ir más allá en su valoración. Su interés, como antes indicábamos, reside en la confirmación de que la historia del relleno de la cavidad es más amplia de lo que se deducía en la valoración de los materiales de las excavaciones de Viñes y Jordá, pues resulta evidente que los paquetes del Pleistoceno Superior correspondientes a los MIs 3 y 2 debieron estar representados en la secuencia del yacimiento, y que su falta de documentación actual in situ remite a un intenso proceso de erosión y redeposición que no sólo parece que afectó a esta parte de la secuencia, sino que seguramente también fue responsable de la eliminación de parte de los niveles del mis 4 y 5 . A esta última suposición apunta la tipología del material del Paleolítico Medio recuperado en el mismo nivel revuelto.

Sin embargo, el principal interés de estos materiales del Paleolítico Superior objeto de estas líneas es que confirman que la ocupación de Cova Negra 
no se limitó al Paleolítico Medio, ni al momento inicial de las secuencia del Paleolítico Superior, y permiten dimensionar el alcance de los procesos de alteración postdeposicional registrados en la cavidad, lo que facilita una mejor comprensión de cuál fue la dinámica del relleno del yacimiento y ayuda a entender las dudas que en su día tuvieron Viñes y Jordá sobre la cronología de los niveles superiores. Unas dudas que también estuvieron presentes en la interpretación de la cronología de los niveles superiores de la secuencia y en la interpretación de esos materiales años después (Villaverde, 1984).

Si comparamos la sucesión estratigráfica de los Sectores o y s del yacimiento, se observa con claridad que la importancia de la alteración postdeposicional es más intensa cuanto más cercana se encuentra la zona estudiada de la pared s de la cueva y aumenta ligeramente hacia la boca de la cavidad. De hecho, en la pared s los procesos de redeposición han llegado a colmatar parte del espacio que corresponde a un desarrollo cavernario que claramente se extiende más allá de la zona actualmente practicable, tal y como se ha comprobado en las campañas más recientes. Esta circunstancia genera una falsa idea del perímetro original y la superficie habitable en los niveles inferiores y medios de la secuencia. Una apreciación semejante llevó a considerar a Viñes que en esa zona se abría una Galería especialmente frecuentada durante el final del Paleolítico medio y el inicio del Paleolítico Superior. Ahora, después de las excavaciones que se están llevando a cabo en esa zona, sabemos que la Galería acumula un importante depósito del nivel superficial revuelto, con la consiguiente mezcla de materiales de los dos periodos.

En el Sector s (Fig. 6) el nivel revuelto descansa directamente sobre los Niveles V-VII, mientras que en el Sector o apoya sobre los Niveles I-v. El Nivel I no ofrece dudas de su adscripción al Paleolítico Medio y sobre este debieron situarse los paquetes que ahora aparecen mezclados en el nivel superficial. A la espera de que los trabajos en curso permitan perfilar con mayor detalle la cronología de los Niveles I-IV, por el momento podemos pensar que el nivel revuelto decapitó una parte sustancial del relleno del Pleistoceno Superior, y con bastante probabilidad no sólo los paquetes que se asociaron al Paleolítico Superior - MIs 3 y 2-, sino también los del Paleolítico Medio clásico -MIS 5 y 4 -.

Aunque queda fuera del propósito de este trabajo un estudio detenido de los materiales del $\mathrm{Pa}$ leolítico Medio del nivel superficial, sí que resulta oportuno indicar que las características tecnológicas (buena presencia de la talla Levallois, soportes delgados y buena preparación de las plataformas de percusión), tipológicas - presencia de puntas de tipologías propias de fases avanzadas, como una punta de Soyons, y dominio de las raederas simples convexas- y las materias primas empleadas -buena presencia de sílex procedentes del núcleo de Alcoysugieren unas cronologías propias del Paleolítico Medio clásico, notablemente diferenciadas de las que a nivel regional se documentan en Bolomor en los niveles datados en el Pleistoceno Medio (Fernández, 2007).

No es posible determinar la fase en la que se produjo la primera ocupación del Paleolítico Superior. Los materiales están mezclados y la tipología no permite establecer ni negar con seguridad la existencia de niveles del Auriñaciense. Sí que resulta clara la existencia de Gravetiense y Solutrense, y también resulta probable la presencia de Magdaleniense, lo que implica un proceso relativamente amplio en términos cronológicos, y permite, como ya se ha señalado, vislumbrar el alcance de la remoción sufrida por la parte superior de la secuencia original del yacimiento.

Finalmente, la constatación de que Cova Negra fue ocupada durante distintas etapas del Paleolítico Superior no resulta sorprendente en términos territoriales, habida cuenta de que a pocos metros de distancia de Cova Negra, aguas arriba en la misma orilla del río Albaida, en la Cova de l'Assut de Bellús (Tiffagom y Sanchis, 2008) se localizaron un par de valvas perforadas de Pecten sp. que han sido relacionadas con el Paleolítico Superior. Por otra parte, Cova Negra se encuentra a menos de $20 \mathrm{~km}$ a vuelo de pájaro de los importantes conjuntos arqueológicos de Parpalló y Malladetes, y el tránsito entre ellos se facilita a través de buenas vías de comunicación. Además, en un radio de no más de $40 \mathrm{~km}$ se localizan una buena parte de los yacimientos del 
Paleolítico Superior de las comarcas centrales del País Valenciano.

En definitiva, los materiales del Paleolítico Superior que aquí hemos presentado ayudan a comprender el proceso de alteración postdeposicional que la secuencia de Cova Negra registró en una parte importante de su relleno pleistoceno original y facilitan una más ajustada explicación de los problemas que Viñes y Jordá experimentaron a la hora de valorar la cronología de los niveles superiores. Unas dudas que han estado más o menos presentes en posteriores trabajos y que ahora, al menos en lo que respecta a las cronologías del Paleolítico Superior, quedan mejor precisadas.

\section{Bibliografía}

Arsuaga, J. L.; Villaverde, V.; Quam, R.; Martínez, I.; Carretero, J. M.; Lorenzo, C. y Gracia, A. (2007): "New Neandertal remains from Cova Negra (Valencia, Spain)", Journal of Human Evolution, 52, pp. 31-58. doi.org/10.1016/j.jhevol.2006.07.011.

FERnÁndeZ, J. (2007): La Cova del Bolomor (Tavernes de la Valldigna, Valencia). Serie Trabajos Varios del sip, 108. Valencia.

Fortea, J.; Fullola, J. M.; Villaverde, V.; Davidson, I.; Dupré, M. y Fumanal, M. P. (1983): "Schéma paléoclimatique, faunique et chronoestratigraphique des industries à bord abattu de la région méditerranéenne espagnole", Rivista di Scienze Preistoriche, xxxviII, pp. 21-67.

Fortea, J. y JordÁ, F. (1976): "La Cueva de Les Mallaetes y los problemas del Paleolítico Superior del Mediterráneo español”, Zephyrus, xxvi-XxviI, pp. 129-166.

Fullola, J. M. (1979): Las industrias liticas del Paleolitico Superior ibérico. Serie Trabajos Varios del sip, 60. Valencia.

Fullola, J. M.; Román, D.; Soler, N. y Villaverde, V. (2007): "Le Gravettien de la Mediterranéene ibérique”, Paléo, 19, pp. 73-88.

Fumanal, M. P. y Villaverde, V. (2009): "Las excavaciones en la Cova Negra en los años 80, la estratigrafía y el marco cronológico". En Villaverde, V.; Pérez Ballester, J. y Ledo, A. (eds.): Historia de Xátiva. Prehistoria, arqueología y Antigüedad. Xátiva, vol. I, pp. 35-57.

Guillem, P. (2009): "Los micromamíferos (Rodentia, Insectivora y Chiroptera)”. En Villaverde, V.; Pérez
Ballester, J. y Ledo, A. (eds.): Historia de Xàtiva. Prehistoria, Arqueología y Antigüedad. Játiva: Univ. de Valencia, vol. I, pp. 85-114.

JordÁ, F. (1945): "La Cova Negra de Bellús (Játiva) y sus industrias líticas", Archivo de Prehistoria Levantina, II, pp. 11-19.

JordÁ, F. (1953): "Nuevos hallazgos en Cova Negra (Játiva)", Archivo de Prehistoria Levantina, Iv, pp. 7-13.

JordÁ, F. (1956): "Observaciones a la cronología del Musteriense español”, Speleon, 1-4, pp. 155-164.

Martínez Valle, R. (2009): "Restos óseos de macromamíferos y aves". En Villaverde, V.; Pérez Ballester, J. y Ledo, A. (coords.): Historia de Xàtiva. Prehistoria, Arqueología y Antigüedad. Játiva: Univ. de Valencia, vol. I, pp. 59-83.

Peña, P. de la y Vega, L. G. (2013): "Bipolar knapping in Gravettian occupations at El Palomar Rockshelter (Yeste, Southeastern Spain)", Journal of Anthropological Research, 69, pp. 33-64.

Pérez Ripoll, M. (1977): Los mamíferos del yacimiento musteriense de Cova Negra (Játiva, Valencia). Serie Trabajos Varios del sip, 53. Valencia.

Pericot, L. (1942): La Cueva del Parpalló (Gandía). Madrid: CsIC.

Tiffagom, M. y Sanchís, A. (2008): "Excavaciones arqueológicas en la Cova de l'Assut de Bellús. Primeras valoraciones", Archivo de Prehistoria Levantina, 27, pp. 371-380.

Villaaverde, V. (1984): La Cova Negra de Xàtiva y el Musteriense de la región central del Mediterráneo español. Serie Trabajos Varios del sip, 79. Valencia.

Villaverde, V.; Guillem, P.; Martínez-Valle, R. y Eixea, A. (2014): "Cova Negra". En Carbonell, E.; Bermúdez de Castro, J. M. y Arsuaga, J. L. (eds.): Los cazadores recolectores del Pleistoceno y del Holoceno en Iberia y el Estrecho de Gibraltar: Estado actual del conocimiento del registro arqueológico. Burgos: Fundac. Atapuerca-Univ. Burgos, pp. 361-369.

Villaverde, V.; Martínez Valle, R. y Blasco, R. (2009): "Análisis de la industria lítica y de la economía: aproximación al uso del espacio”. En Villaverde, V.; Pérez Ballester, J. y Ledo, A. (eds.): Historia de Xàtiva. Prehistoria, Arqueología y Antigüedad. Jàtiva: Univ. Valencia, vol. I, pp. 147-193.

Villaverde, V. y Peña, J. L. (1981): Piezas con escotadura del Paleolítico Superior valenciano. Serie Trabajos Varios del sip, 69. Valencia.

VIÑEs, G. (1942): Cova Negra de Belluis. Notas sobre las excavaciones practicadas. Serie Trabajos Varios del SIP, 6. Valencia. 